\title{
Tunable NIR absorption property of dithiolene nickel complex: a promising NIR-II absorption material for photothermal therapy
}

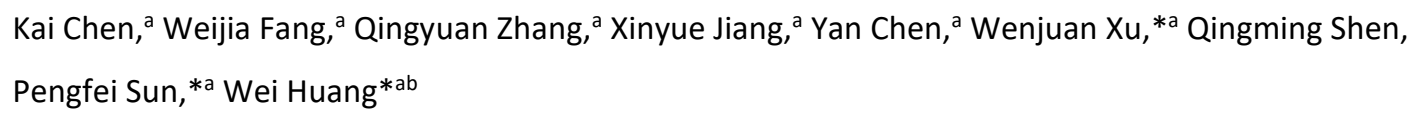

a.Key Laboratory for Organic Electronics and Information Displays \&Jiangsu Key Laboratory for Biosensors, Institute of Advanced Materials (IAM), Jiangsu National Synergetic Innovation Center for Advanced Materials (SICAM), Nanjing University of Posts \& Telecommunications, 9 Wenyuan Road, Nanjing 210023, China. E-mail: iamwjxu@njupt.edu.cn (Wj Xu); iampfsun@njupt.edu.cn (Pf Sun)

b. Shanxi Institute of Flexible Electronics (SIFE), Northwestern Polytechnical University (NPU), 127 West Youyi Road, Xi'an 710072, Shanxi, China. Email:iamwhuang@nwpu.edu.cn

\section{Experimental}

\section{Materials}

All starting compounds and organic solvents were purchased from commercial suppliers and directly used without purification. Tetrahydrofuran (THF) was dried with potassium hydroxide overnight, and then refluxed on sodium for 12 hours using diphenylmethanone as indicator. Benzil, 2-bromofluorene, 3-bromocarbazole, bromohexane, n-Butyllithium (2.5 $\left.\mathrm{mol} \cdot \mathrm{L}^{-1}\right), 1$,4-dioxane and nickel (II) chloride hexahydrate puratrem $\left(\mathrm{NiCl}_{2} \cdot 6 \mathrm{H}_{2} \mathrm{O}\right)$ were purchased from Shanghai Energy Chemical Co. Ltd. Pluronic ${ }^{\circledR}$ F-127 were purchased from Sigma-Aldrich. Other reagents and solvents were from Sinopharm Chemical Reagent Co., Ltd.

\section{Instruments and Characterization}


${ }^{1} \mathrm{H}$ NMR spectra were recorded on Bruker Ultra Shield Plus $400 \mathrm{MHz}$ nuclear magnetic resonance spectrometer using d-chloroform solution at room temperature. Dynamic light scattering (DLS) analysis was measured by a commercial light scattering spectrometer (ALV/CGS-3; ALV, Langen, Germany) outfit with a multi- $\tau$ digital time correlator (ALV-7004; ALV, Langen, Germany) and a He-Ne laser at $\lambda=632.8$ $\mathrm{nm}$ ). The morphology of nanoparticles was observed by a transmission electron microscope (TEM, Hitachi HT7700), whose acceleration voltage is $100 \mathrm{KV}$. Five microliter NiBD-Cz NPs suspension were deposited at the surface of carbon support films (230 mesh) without staining. The UV-vis-NIR absorption spectra were recorded on a Shimadzu UV-3600 spectrophotometer at $25.0 \pm 0.5^{\circ} \mathrm{C}$. All photothermal tests were conducted by Fotric 225 (IR thermal camera, $\pm 2^{\circ} \mathrm{C}$ ), which was bought from Fotric. (Shanghai, China). The methyl thiazolyl tetrazolium (MTT) assay were studied by a PowerWave XS/XS2 microplate spectrophotometer (BioTek, Winooski, VT).

\section{Synthesis of 2-Bromo-9,9-dihexyl-fluorene}

2-Bromo-9,9-dihexyl-fluorene was synthesized via previous report ${ }^{1}$ and obtained as a colorless viscous liquid in the yield of 99\%. ${ }^{1} \mathrm{H}$ NMR (400 MHz, Chloroform-d) $\delta 7.69-7.64(\mathrm{~m}, 1 \mathrm{H}), 7.56$ $(\mathrm{dd}, \mathrm{J}=7.9,0.7 \mathrm{~Hz}, 1 \mathrm{H}), 7.48-7.43(\mathrm{~m}, 2 \mathrm{H}), 7.36-7.30(\mathrm{~m}, 3 \mathrm{H}), 1.95(\mathrm{ddt}, 4 \mathrm{H}), 1.18-1.00(\mathrm{~m}$, 12H), $0.78(\mathrm{t}, \mathrm{J}=7.1 \mathrm{~Hz}, 6 \mathrm{H}), 0.62(\mathrm{dq}, \mathrm{J}=14.2,7.4 \mathrm{~Hz}, 4 \mathrm{H})$.

\section{Synthesis of 3-Bromo-N-hexyl-carbazole}

3-Bromo-N-hexyl-carbazole was synthesized via previous report ${ }^{2}$ and obtained as a white solid in the yield of $90 \% .{ }^{1} \mathrm{H}$ NMR (400 MHz, Chloroform-d) $\delta 8.18(\mathrm{~d}, \mathrm{~J}=1.9 \mathrm{~Hz}, 1 \mathrm{H}), 8.03(\mathrm{dd}, \mathrm{J}=7.9$, $1.2 \mathrm{~Hz}, 1 \mathrm{H}), 7.55-7.44(\mathrm{~m}, 2 \mathrm{H}), 7.38(\mathrm{~d}, \mathrm{~J}=8.2 \mathrm{~Hz}, 1 \mathrm{H}), 7.25-7.18(\mathrm{~m}, 2 \mathrm{H}), 4.23(\mathrm{t}, \mathrm{J}=7.2 \mathrm{~Hz}$, 2H), $1.82(\mathrm{p}, \mathrm{J}=7.3 \mathrm{~Hz}, 2 \mathrm{H}), 1.41-1.21(\mathrm{~m}, 7 \mathrm{H}), 0.90-0.80(\mathrm{~m}, 3 \mathrm{H})$. 


\section{General procedures for the preparation of 1,2-Diketone compounds}

Bromide (2 equiv) was dissolved in THF in a two-necked round-bottomed flask filled with nitrogen, and its temperature was reduced to $-78^{\circ} \mathrm{C}$, and stirred at a low temperature for 10 minutes.

Then n-BuLi (2.5 mol $\cdot \mathrm{L}^{-1}, 2$ equiv) dropwise was added and kept stirring at low temperature for 150 minutes to obtain mixed solution $\mathrm{A}$. The $\mathrm{LiBr}(2$ equiv) and $\mathrm{CuBr}$ ( 2 equiv) were dissolved in THF in a two-necked round-bottomed flask under nitrogen atmosphere and cooled to $-40^{\circ} \mathrm{C}$ to obtain the solution B. $\mathrm{C}_{2} \mathrm{O}_{2} \mathrm{Cl}_{2}$ (1 equiv) was dissolved in THF in a two-necked round-bottomed flask under nitrogen atmosphere, and the temperature was lowered to $-40^{\circ} \mathrm{C}$ to obtain solution $\mathrm{C}$. Solution A was added to B and stirred for 5 minutes, then solution C was added to B slowly and kept at $-40^{\circ} \mathrm{C}$ and stirred for 2.5 hours. The system was then warmed to room temperature for another 12 hours. After the reaction was completed, the mixture was extracted by water and dichloromethane. The separated organic component was washed with saturated salt water. Residual water is removed with anhydrous $\mathrm{MgSO}_{4}$. The target product was obtained after the mixture was purified by column chromatography whose solvent was removed by rotative evaporator.

1,2-Bis(9,9- dihexyl-fluorenyl-2-yl)-1,2-dione was obtained as a yellow solid in the yield of 53\%. ${ }^{1} \mathrm{H}$ NMR (400 MHz, Chloroform-d) $\delta 8.10(\mathrm{~d}, \mathrm{~J}=1.5 \mathrm{~Hz}, 2 \mathrm{H}), 7.90(\mathrm{dd}, \mathrm{J}=7.9,1.5 \mathrm{~Hz}, 2 \mathrm{H}), 7.77$ $(\mathrm{d}, \mathrm{J}=8.0 \mathrm{~Hz}, 4 \mathrm{H}), 7.41-7.37(\mathrm{~m}, 6 \mathrm{H}), 2.01(\mathrm{ddd}, \mathrm{J}=8.7,6.6 \mathrm{~Hz}, 10 \mathrm{H}), 1.09(\mathrm{p}, \mathrm{J}=6.1,5.5 \mathrm{~Hz}$ 20H), $0.76(\mathrm{t}, \mathrm{J}=7.1 \mathrm{~Hz}, 18 \mathrm{H}), 0.59$ (t, J = 8.3 Hz, 8H). 
1,2-Bis(9-hexyl-carbazol-3-yl) -1,2-dione was obtained as a yellow solid in the yield of $47 \% .{ }^{1} \mathrm{H}$ NMR (400 MHz, Chloroform-d) $\delta 8.80(\mathrm{~s}, 2 \mathrm{H}), 8.25-8.18(\mathrm{~m}, 2 \mathrm{H}), 8.11(\mathrm{~d}, \mathrm{~J}=7.8 \mathrm{~Hz}, 2 \mathrm{H}), 7.51$ $(\mathrm{t}, \mathrm{J}=7.6 \mathrm{~Hz}, 2 \mathrm{H}), 7.45(\mathrm{t}, \mathrm{J}=9.1 \mathrm{~Hz}, 4 \mathrm{H}), 7.33-7.24(\mathrm{~m}, 3 \mathrm{H}), 4.33(\mathrm{t}, \mathrm{J}=7.2 \mathrm{~Hz}, 4 \mathrm{H}), 2.01(\mathrm{~d}$, $\mathrm{J}=6.5 \mathrm{~Hz}, 1 \mathrm{H}), 1.88(\mathrm{p}, \mathrm{J}=7.3 \mathrm{~Hz}, 4 \mathrm{H}), 1.38(\mathrm{~s}, 5 \mathrm{H}), 1.36-1.24(\mathrm{~m}, 17 \mathrm{H}), 0.86(\mathrm{t}, \mathrm{J}=6.9 \mathrm{~Hz}$, $7 \mathrm{H})$.

\section{General procedures for the preparation of NiBDs}

NiBDs were synthesized via previous report ${ }^{3}$.

NiBD-Ph was obtained as a dark green solid in the yield of $60 \% .{ }^{1} \mathrm{H}$ NMR $(400 \mathrm{MHz}$, Chloroformd) $\delta 7.38(\mathrm{dtd}, \mathrm{J}=7.6,4.6,4.2,1.7 \mathrm{~Hz}, 13 \mathrm{H}), 7.29(\mathrm{~d}, \mathrm{~J}=7.5 \mathrm{~Hz}, 7 \mathrm{H})$. MS(MALDI-TOF) [m/z]: 543.846 .

NiBD-Fl was obtained as a dark green solid in the yield of 47\%. ${ }^{1} \mathrm{H}$ NMR $(400 \mathrm{MHz}$, Chloroformd) $\delta 7.65(\mathrm{~d}, \mathrm{~J}=6.4 \mathrm{~Hz}, 4 \mathrm{H}), 7.55(\mathrm{~d}, \mathrm{~J}=7.9 \mathrm{~Hz}, 4 \mathrm{H}), 7.49-7.39(\mathrm{~m}, 6 \mathrm{H}), 7.31(\mathrm{~d}, \mathrm{~J}=3.7 \mathrm{~Hz}$, 14H), $1.82(\mathrm{dd}, \mathrm{J}=25.4,10.7 \mathrm{~Hz}, 17 \mathrm{H}), 1.57(\mathrm{~s}, 11 \mathrm{H}), 1.26(\mathrm{~s}, 6 \mathrm{H}), 1.14-0.92(\mathrm{~m}, 31 \mathrm{H}), 0.77(\mathrm{t}$, $\mathrm{J}=7.0 \mathrm{~Hz}, 26 \mathrm{H}), 0.58(\mathrm{~d}, \mathrm{~J}=36.5 \mathrm{~Hz}, 21 \mathrm{H}) . \mathrm{MS}(\mathrm{MALDI}-\mathrm{TOF})[\mathrm{m} / \mathrm{z}]: 1569.414$

NiBD-Cz was obtained as a dark green solid in the yield of 34\%. ${ }^{1} \mathrm{H}$ NMR $(400 \mathrm{MHz}$, Chloroformd) $\delta 8.12(\mathrm{dt}, \mathrm{J}=7.8,1.0 \mathrm{~Hz}, 2 \mathrm{H}), 7.51-7.39(\mathrm{~m}, 4 \mathrm{H}), 7.24(\mathrm{ddd}, \mathrm{J}=8.0,6.9,1.1 \mathrm{~Hz}, 2 \mathrm{H}), 4.31$ (t, J = 7.3 Hz, 2H), $1.88(\mathrm{p}, \mathrm{J}=7.3 \mathrm{~Hz}, 2 \mathrm{H}), 1.47-1.21(\mathrm{~m}, 8 \mathrm{H}), 0.94-0.82(\mathrm{~m}, 3 \mathrm{H})$.

\section{Preparation of NiBD-Cz NPs Suspension}


$5 \mathrm{mg}$ NiBD-Cz was dissolved in $10 \mathrm{~mL}$ of THF as the organic phase. Then the $2 \mathrm{~mL}$ of organic phase solution was added to a solution of amphiphilic block copolymer F-127 in ultrapure water (10 mL) under vigorous sonication. The system was fully dissolved by ultrasonication with a cell pulverizer. Then, the above-mentioned mixed solution was fully evaporated to remove the organic solvent tetrahydrofuran by rotary evaporator at $50^{\circ} \mathrm{C}$. The NiBD-Cz NPs suspension with a concentration of $0.1 \mathrm{mg} \cdot \mathrm{mL}^{-1}$ was obtained.

\section{DFT studies}

Density functional theory (DFT) is implemented in the Gaussian 09 program using the B3LYP hybrid function. The basis set for $\mathrm{C}, \mathrm{N}, \mathrm{S}$, and $\mathrm{H}$ atoms is $6-311 \mathrm{G}^{* *}$ and $\mathrm{Ni}$ atom is LanL2DZ.

\section{Photothermal Activity}

The PCE ( $)$ was calculated according to a previously described equation 1. A $200 \mu \mathrm{L}$ NiBD-Cz NPs aqueous solution was added to a centrifuge tube and illuminated by a $1064 \mathrm{~nm}$ laser for $6 \mathrm{~min}$. The temperature changes were monitored by an infrared thermal camera and were recorded every $30 \mathrm{~s}$ throughout the laser irradiating time and cooling time. According to the obtained data and equation, the PCE of the NiBD-Cz/F-127 was determined to be $63.6 \%$.

$$
\eta=\frac{h s\left(T_{\max }-T_{\text {sur }}\right)-Q_{0}}{I\left(1-10^{-A_{\lambda}}\right)}
$$

where $h$ is the heat-transfer coefficient, $s$ is the surface area of the container, $T_{\max }-T_{\text {sur }}$ is the maximum temperature change of NiBD-CZ NPs suspension, $I$ is the power of the laser, $A_{\lambda}$ is the absorbance of the NiBD-CZ NPs suspension at $1064 \mathrm{~nm}$. $Q_{0}$ is the heat dissipated from light absorbed with water.

\section{NIR-II Tissue Penetration Depth}


First, a NiBD-Cz NPs suspension with a concentration of $0.08 \mathrm{mg} \cdot \mathrm{mL}^{-1}$ was prepared, and then the frozen chicken tissue was cut out to a thickness of $1 \mathrm{~cm}$ as a base and cut out different thicknesses $(1,2,3,4 \mathrm{~mm})$. The prepared suspension was filled with a centrifuge tube with a capacity of 200 microliters and placed on the chicken tissue base. Then a $1064 \mathrm{~nm}$ laser $\left(1 \mathrm{~W} \cdot \mathrm{cm}^{-}\right.$

${ }^{2}$ ) was used to irradiate centrifuge tubes covered with chicken tissues of different thicknesses. The temperature change was recorded by an infrared thermal camera.

\section{Cell culture and cytotoxicity assay}

In vitro cytotoxicity of the NiBD-Cz NPs was determined in Hela cells by MTT (3-(4,5dimethylthiazol2-yl)-2,5-diphenyl tetrazolium bromide) assay. Hela cells were co-cultured with different doses of NiBD-Cz NPs in Dulbecco's modified Eagle's medium (DMEM) on a 96-well plate with a $5 \% \mathrm{CO} 2$ environment for $24 \mathrm{~h}$. The concentration of NiBD-Cz NPs in the culture medium ranged from 0 to $40 \mu \mathrm{g} \cdot \mathrm{mL}^{-1}$. Formazan crystals were produced following the addition of $20 \mu \mathrm{L}$ of MTT $\left(5.0 \mathrm{mg} \cdot \mathrm{mL}^{-1}\right)$ solution to each well and incubation for $4 \mathrm{~h}$ at $37^{\circ} \mathrm{C}$. Next, the upper supernatant was removed, the formazan crystals were dissolved by $200 \mu \mathrm{L}$ of DMSO. The system was completely mixed by shaking for 10 minutes. The absorbance was then evaluated at a wavelength of $490 \mathrm{~nm}$ using a PowerWave XS/XS2 spectrophotometer. The cell viability was calculated by comparing the absorption values of each sample with the absorption values of untreated cells.

\section{In vitro phototoxicity assay}


Hela cells were co-cultured with different doses of NiBD-Cz NPs in Dulbecco's modified Eagle's medium (DMEM) on a 96-well plate with a $5 \% \mathrm{CO}_{2}$ environment for $24 \mathrm{~h}$. The concentration of NiBD-Cz NPs in the culture medium ranged from 0 to $40 \mu \mathrm{g} \cdot \mathrm{mL}^{-1}$. Then the NiBD-Cz NPs was replaced with DMEM. The 96-well plate was irradiated one by one by a $1064 \mathrm{~nm}$ laser $\left(1 \mathrm{~W} \cdot \mathrm{cm}^{-2}\right)$ for 6 minutes. Next, the upper supernatant was removed. Formazan crystals were produced following the addition of $20 \mu \mathrm{L}$ of MTT $\left(5.0 \mathrm{mg} \cdot \mathrm{mL}^{-1}\right)$ solution to each well and incubation for $4 \mathrm{~h}$ at $37^{\circ} \mathrm{C}$. Next, the upper supernatant was removed, the formazan crystals were dissolved by 200 $\mu \mathrm{L}$ of DMSO. The system was completely mixed by shaking for 10 minutes. The absorbance was then evaluated at a wavelength of $490 \mathrm{~nm}$ using a PowerWave XS/XS2 spectrophotometer. The cell viability was calculated by comparing the absorption values of each sample with the absorption values of untreated cells.

\section{Confocal imaging}

Hela cells were seeded in confocal laser scanning microscope (CLSM) culture dishes (Costar) until the cell population increased to $1 \times 10^{5}$ cells $\mathrm{mL}^{-1}$. The NiBD-Cz/F-127 were then added to the DMEM medium to obtain the mixture medium $\left(0.1 \mathrm{mg} \cdot \mathrm{mL}^{-1}\right)$. After Hela cells incubated with this mixture medium for $4 \mathrm{~h}$ in the dark, the NiBD-Cz/F-127 mixture suspensions were removed and were replaced with DMEM. Next, the selected culture dishes were illuminated by a $1064 \mathrm{~nm}$ laser $\left(1 \mathrm{~W} \cdot \mathrm{cm}^{-2}\right)$ for 6 minutes. After $24 \mathrm{~h}$ apoptosis, the cells were washed twice to remove the cell debris and stained with calcein-AM/propidium iodide (PI) dye. Finally, the cells were imaged by CLSM.

\section{NMR data}




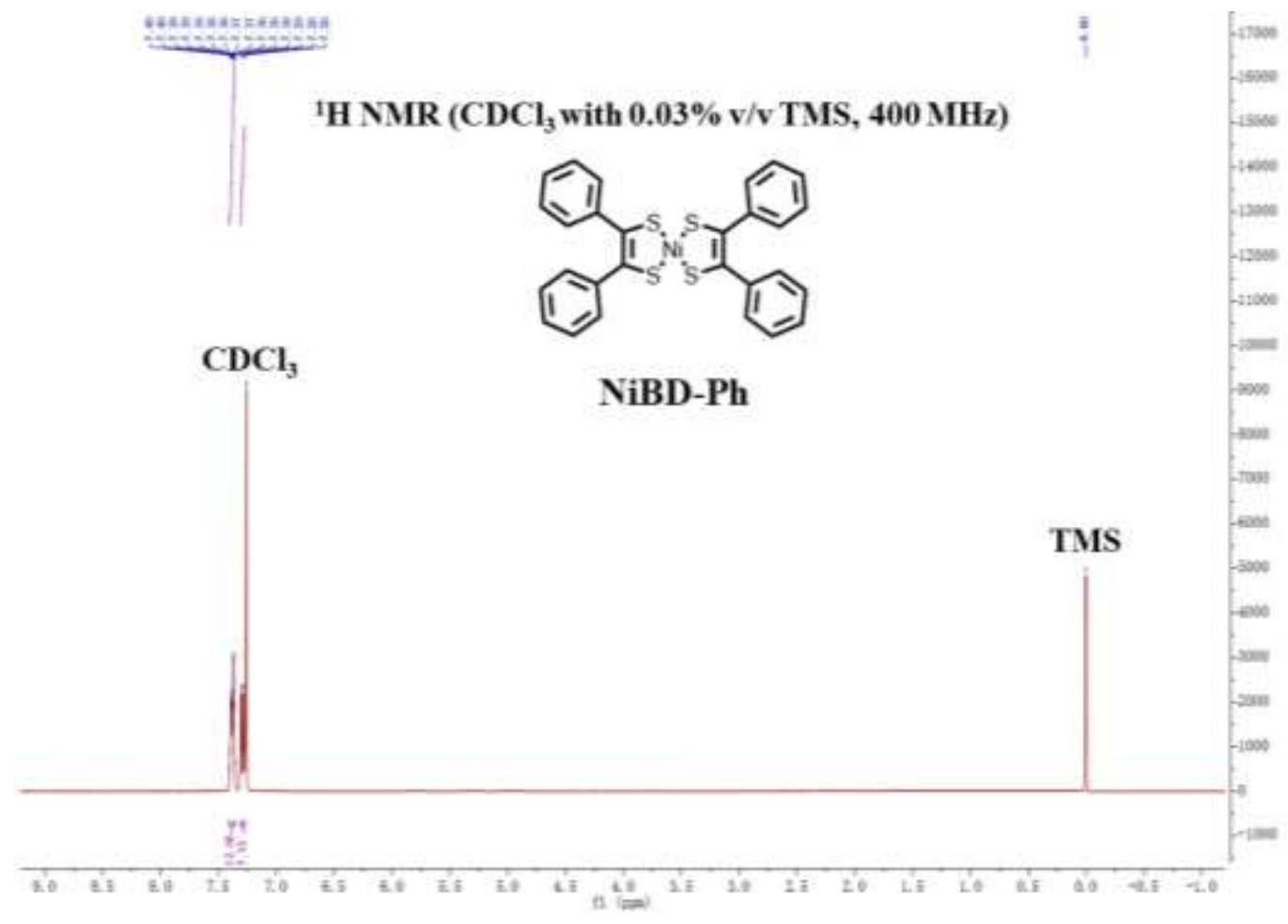

Figure. S1 ${ }^{1} \mathrm{H}$ NMR spectrum of NiBD-Ph

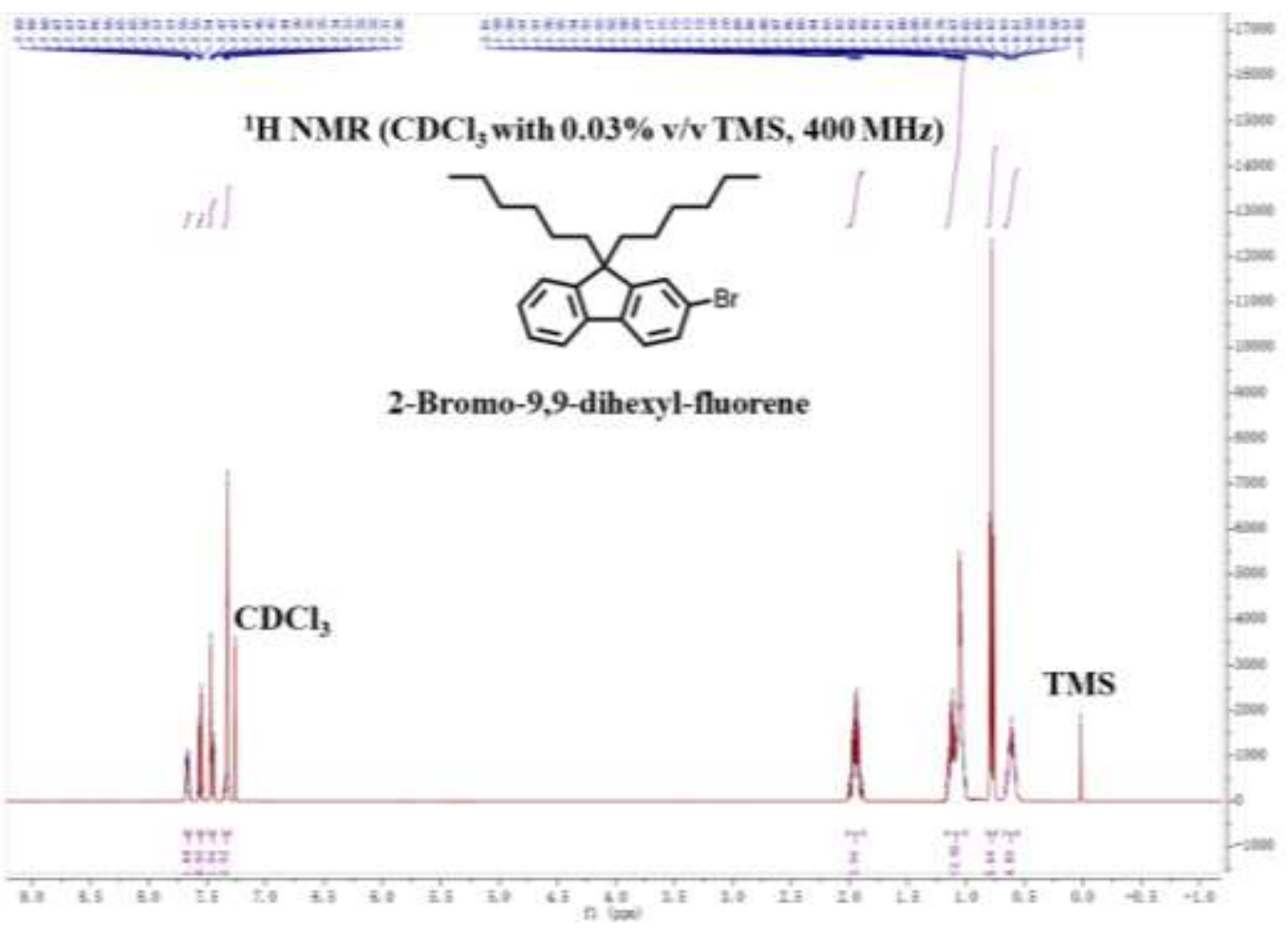

Figure. S2 ${ }^{1} \mathrm{H}$ NMR spectrum of 2-Bromo-9,9-dihexyl-fluorene 




Figure. S3 ${ }^{1} \mathrm{H}$ NMR spectrum of 1,2-Bis(9,9- dihexyl-fluorenyl-2-yl)-1,2-dione

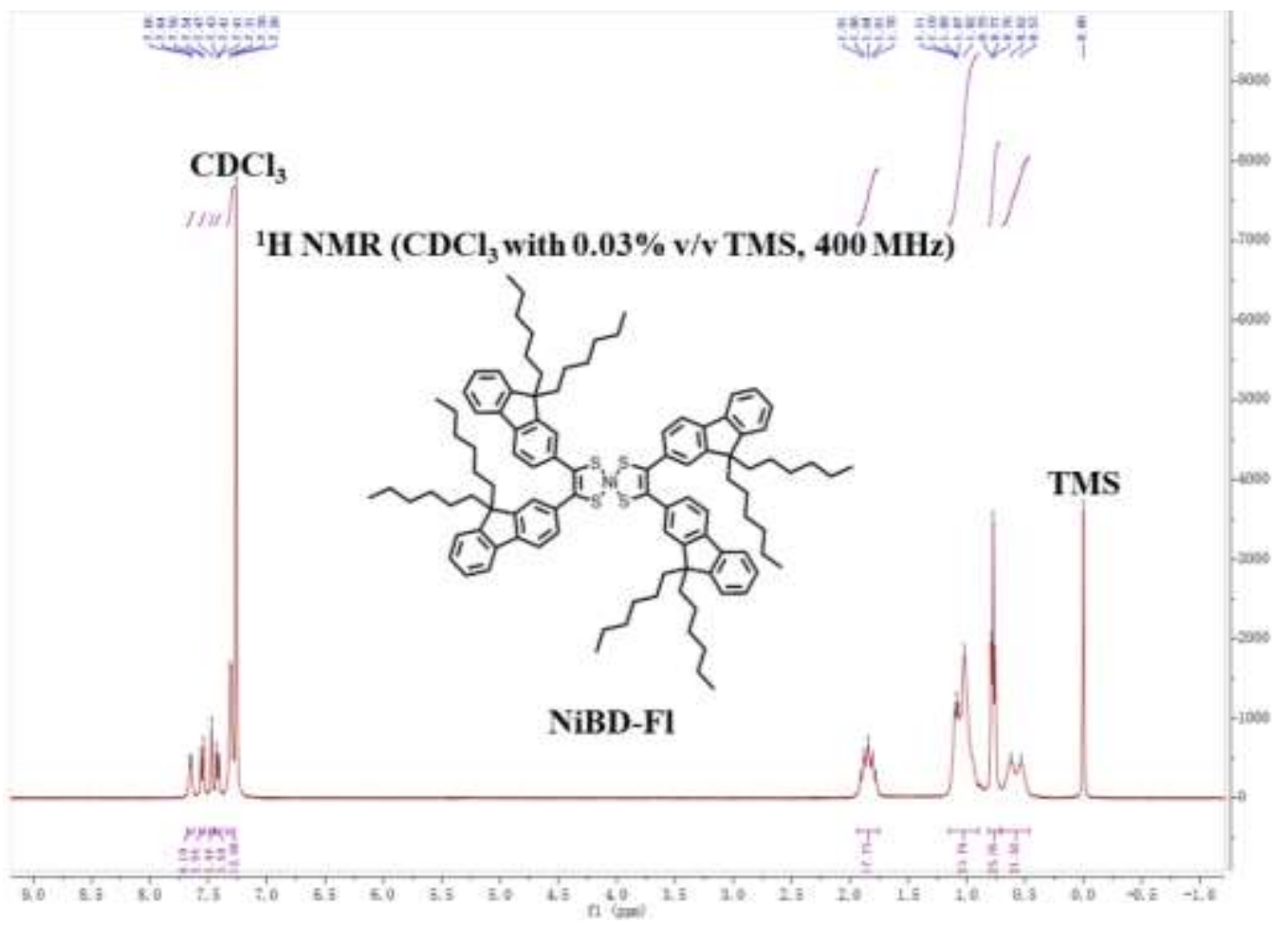

Figure. S4 ${ }^{1} \mathrm{H}$ NMR spectrum of NiBD-Fl 


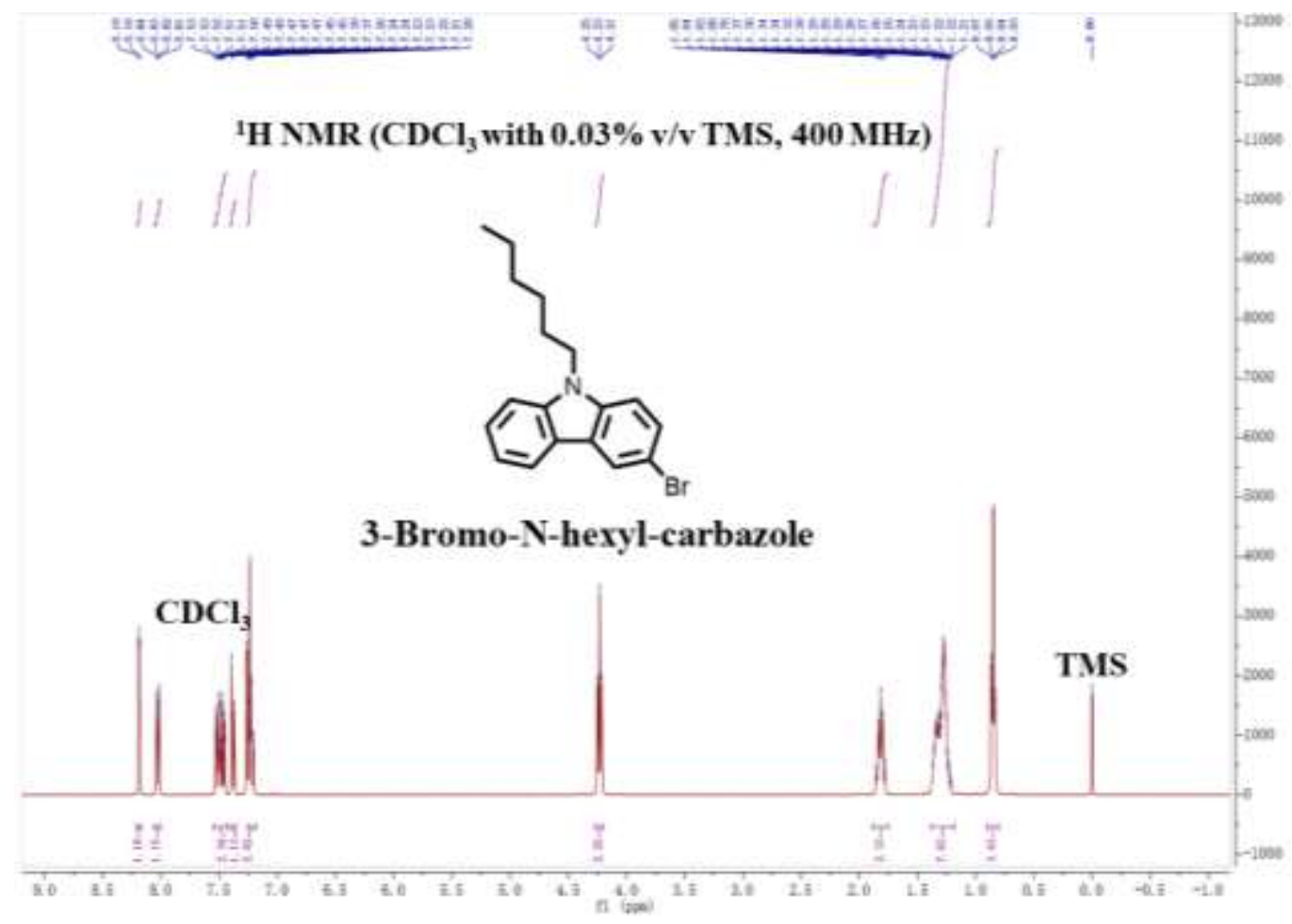

Figure. S5 ${ }^{1} \mathrm{H}$ NMR spectrum of 3-Bromo-N-hexyl-carbazole

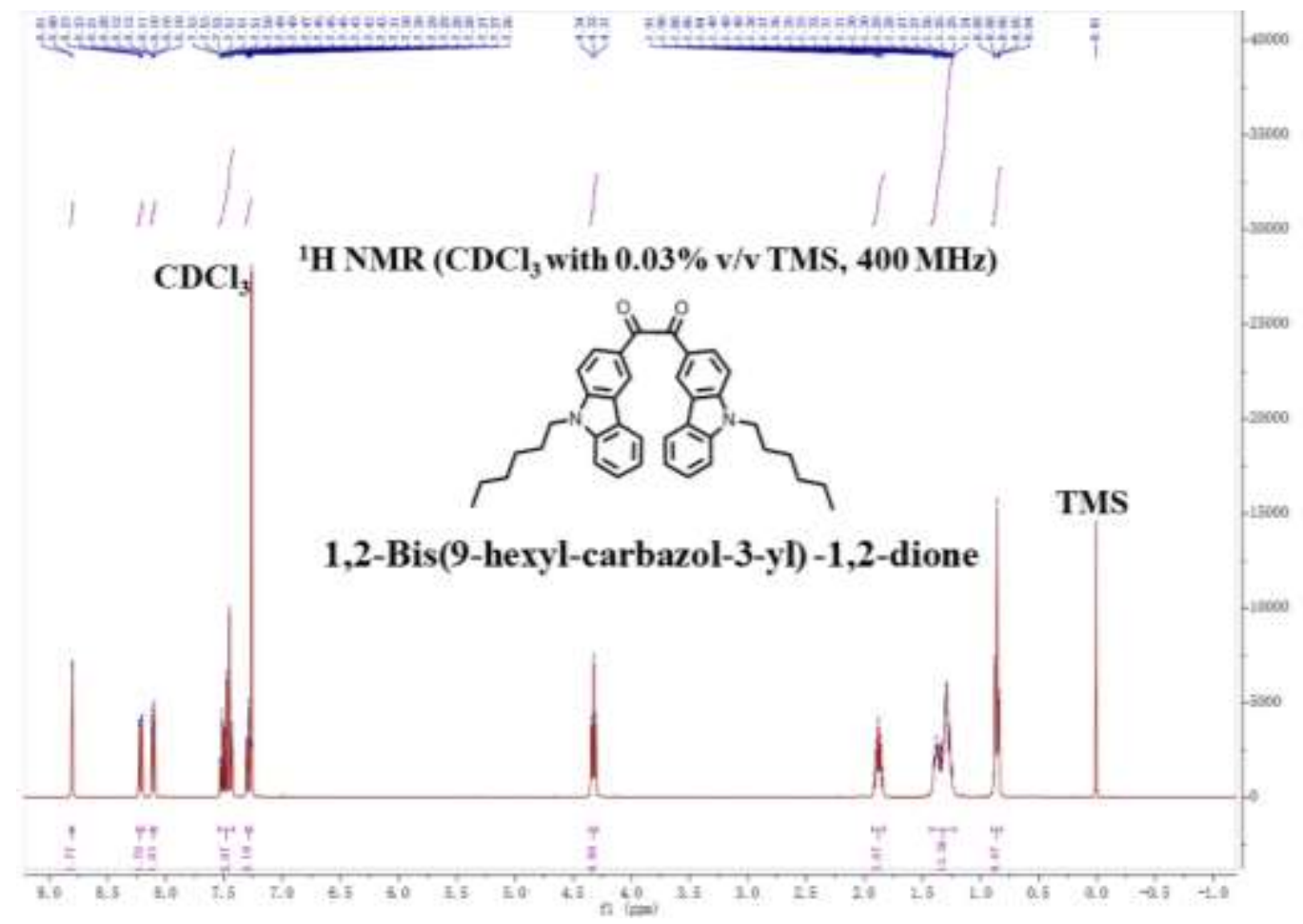

Figure. S6 ${ }^{1} \mathrm{H}$ NMR spectrum of 1,2-Bis(9-hexyl-carbazol-3-yl) -1,2-dione 


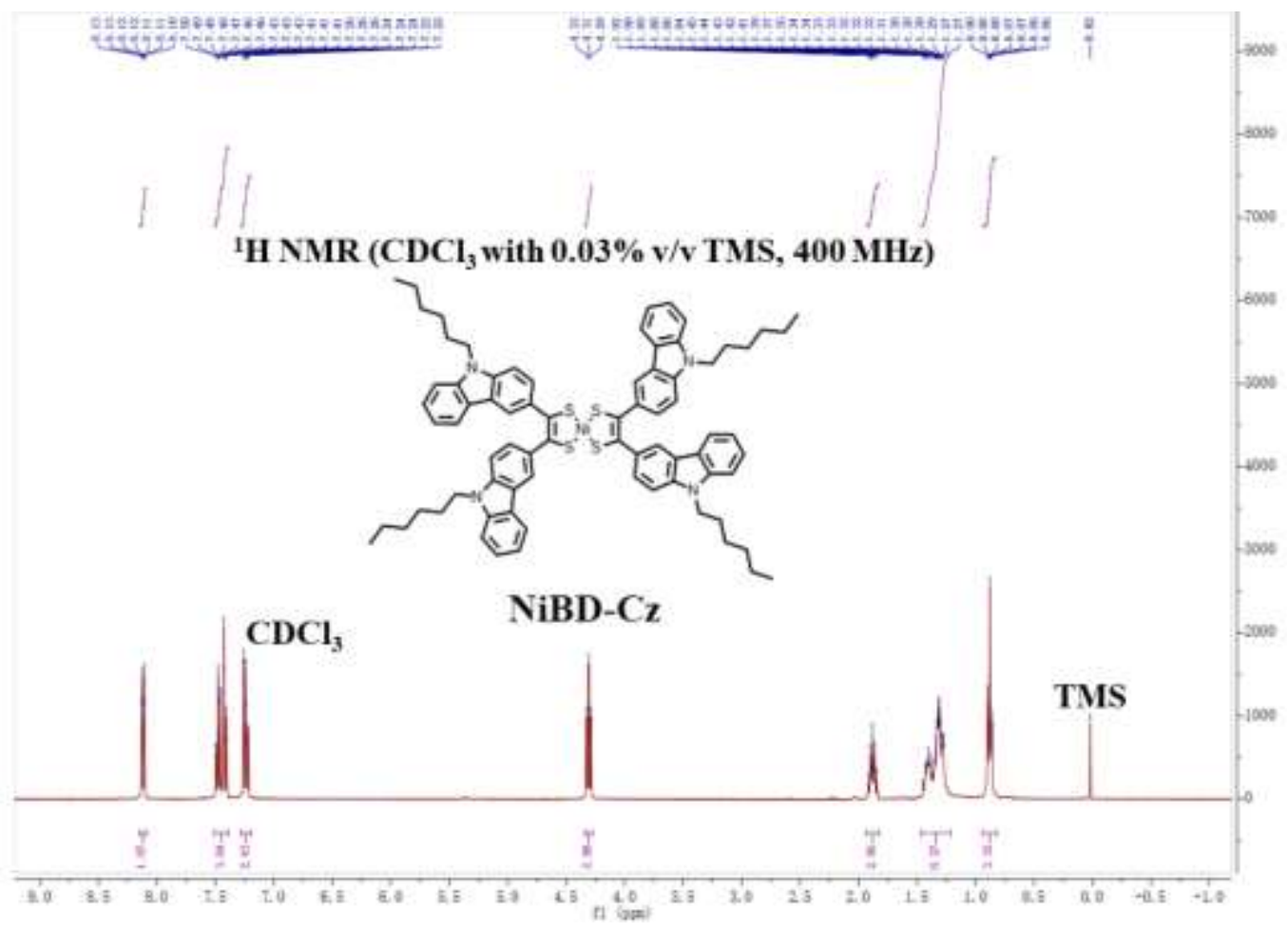

Figure. S7 ${ }^{1} \mathrm{H}$ NMR spectrum of NiBD-Cz

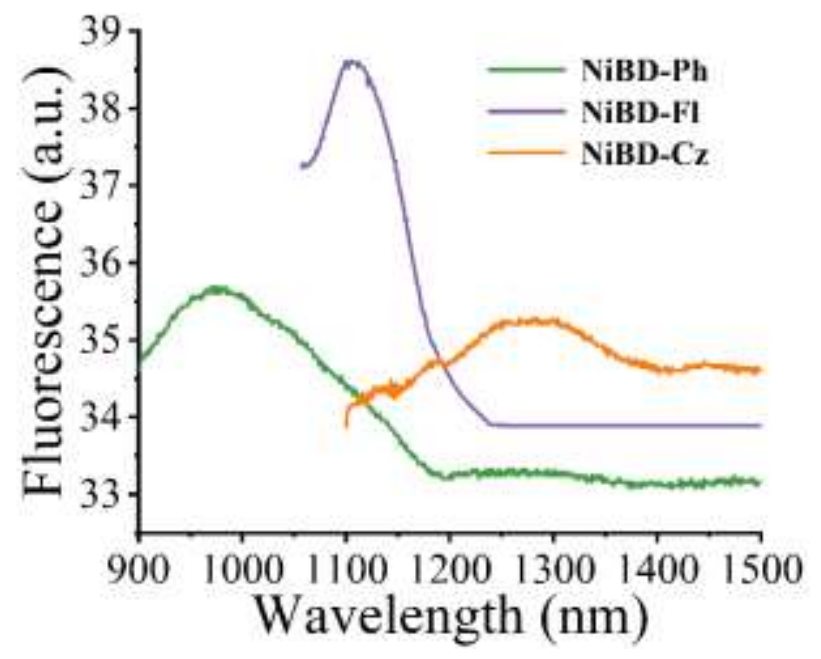

Figure. S8 Normalized NIR emission spectra of NiBDs in THF. 


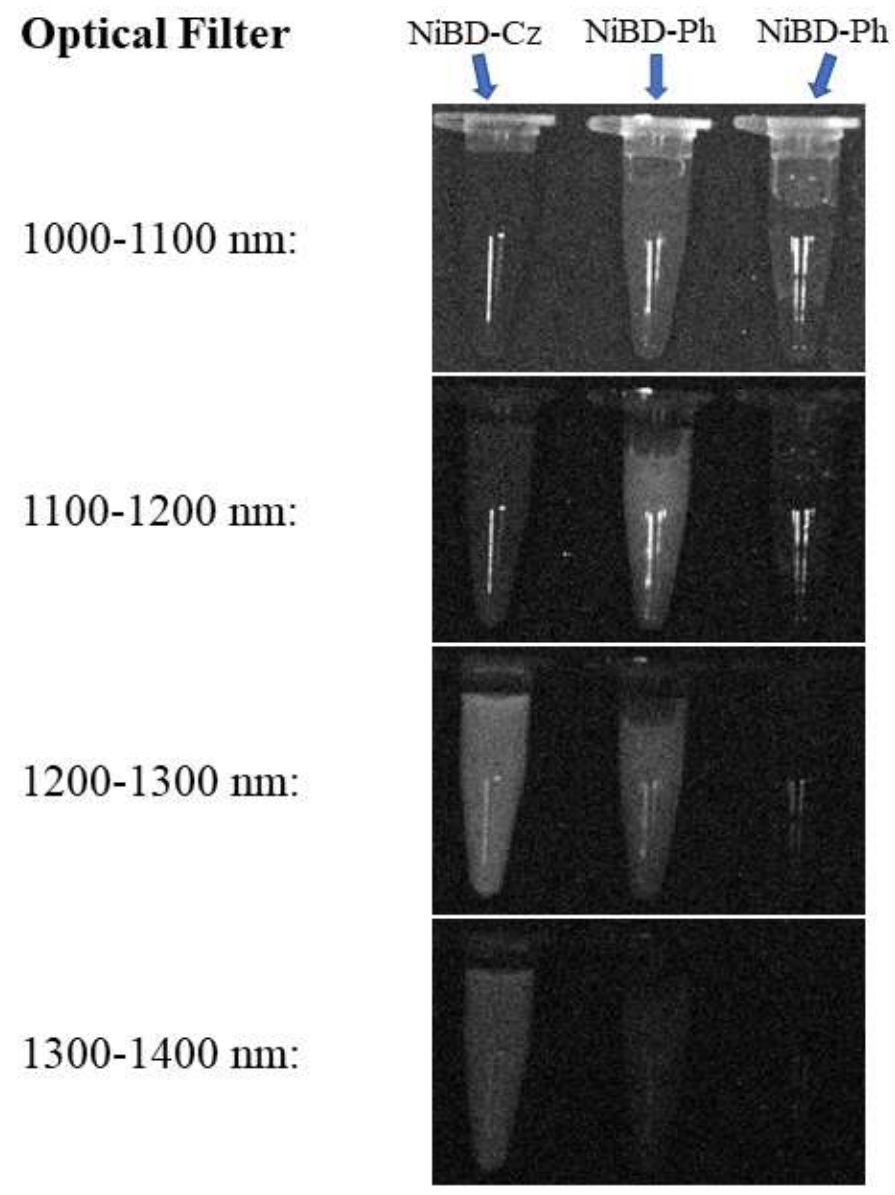

Figure. S9 NIR-II region fluorescence imaging of NiBD-Ph, NiBD-Fl and NiBD-Cz at different wavelength of optical filters, respectively.

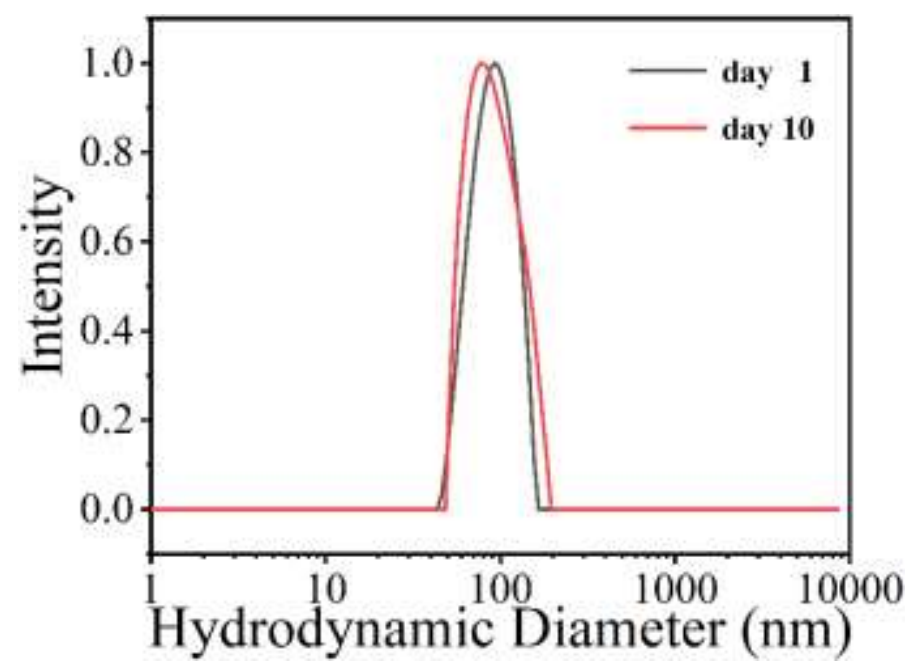

Figure. S10 DLS profile of NiBD-Cz NPs in water on the 1th and 10th days, respectively. 


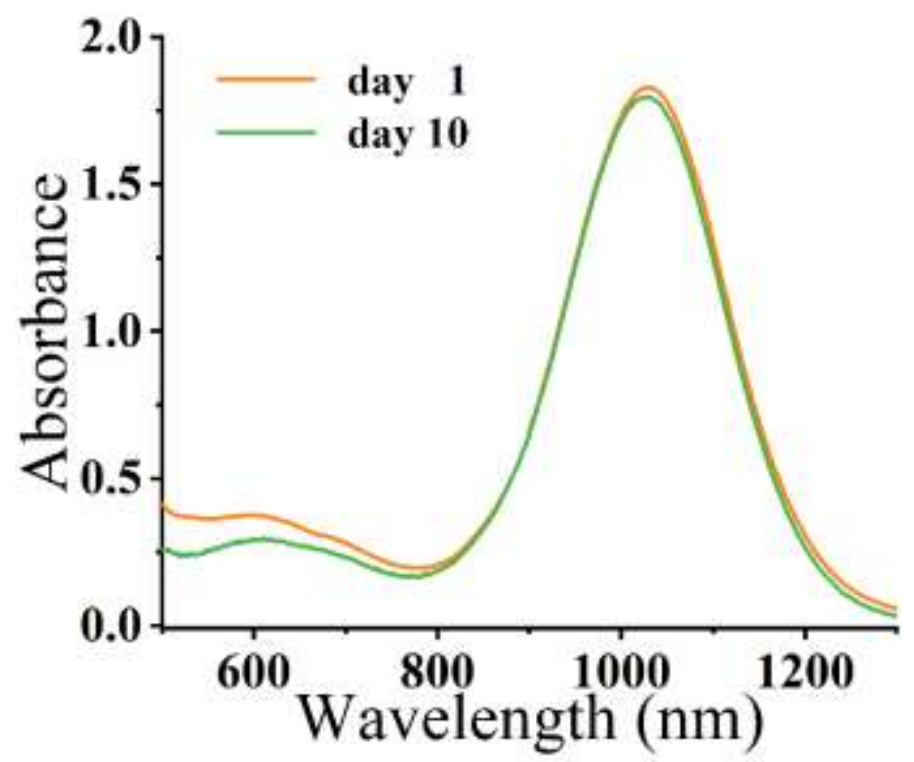

Figure. S11 Absorption spectra of NiBD-Cz NPs in water with concentration of $0.1 \mathrm{mg} \cdot \mathbf{m L}^{-}$

${ }^{1}$ on the 1th and 10th days, respectively.

\section{Reference}

1. Dudek, S. P.; Pouderoijen, M.; Abbel, R.; Schenning, A. P. H. J.; Meijer, E. W., Synthesis and energy-transfer properties of hydrogen-bonded oligofluorenes. In Journal of the American Chemical Society, 2005; Vol. 127, pp 11763-11768.

2. Naik, P.; Su, R.; Elmorsy, M. R.; Babu, D. D.; El-Shafei, A.; Adhikari, A. V., Molecular design and theoretical investigation of new metal-free heteroaromatic dyes with $D-\pi-A$ architecture as photosensitizers for DSSC application. Journal of Photochemistry and Photobiology A: Chemistry 2017, $345,63-73$.

3. Liu, Y.; Zhang, Z.; Chen, X.; Xu, S.; Cao, S., Near-infrared absorbing dyes at $1064 \mathrm{~nm}$ : Soluble dithiolene nickel complexes with alkylated electron-donating groups as Peripheral substituents. Dyes and Pigments 2016, 128, 179-189. 